\title{
50 Years of Psychotherapy: Erudition, Evolution, and Evaluation
}

\author{
James C. Overholser ${ }^{1}[0$ \\ Published online: 27 September 2019 \\ (c) Springer Science+Business Media, LLC, part of Springer Nature 2019
}

\begin{abstract}
The field of psychotherapy has evolved tremendously over the last 50 years. In coordination with the publication of volume 50 of the Journal of Contemporary Psychotherapy, a historical review examines changes in the field. Most published articles have shifted their foundation from theoretical notions based on clinical case material to empirical studies based on treatment-outcome research. Along with these changes, the field has strengthened its scientific foundation, but weakened its clinical application. Overall, a historical review of the past 50 years results in a state of eudaimonia, the feeling of a healthy state of fulfillment and contentment.
\end{abstract}

Keywords Psychotherapy $\cdot$ Scholarship $\cdot$ Publishing

\section{Erudition}

The Journal of Contemporary Psychotherapy was developed by the professional staff of the Long Island Consultation Center located in Queens, New York. Beginning in 1957, it appeared as a newsletter distributed to the staff and affiliates in order to enhance professional development and training in the local area. Quickly, it grew in popularity and was published as a small journal. The first issue was published in 1960 as the Journal of the Long Island Consultation Center. Finally, in 1969, the publication evolved onto the Journal of Contemporary Psychotherapy.

Wil Quaytman served as founding editor, assisted by his friend and colleague Robert Moteki. Dr. Quaytman continued as editor for an impressive 24 years, from 1960 through 1984 , and he played a vital role in helping the publication grow from a local newsletter into a national scholarly journal. When Wil stepped down, the role of editor was

The Journal of Contemporary Psychotherapy is celebrating its 50th year in publication. To honor the contributions made through the journal, the editor-in-chief reflects on important publications, changes in the field, and progress that has been observed in psychotherapy and scholarly publications across the past 50 years.

James C. Overholser

overholser@case.edu

1 Department of Psychology, Case Western Reserve University, 10900 Euclid Avenue, Cleveland, OH 4106-7123, USA transferred to Gerald Albert (1985-1986), Erwin Parson (1987-1999), and Ira Moses (1999-2002). As noted in an early guide for prospective authors, Dr. Quaytman wanted to "avoid the statistical obscurantism, fragmentation, and professional pettifogging" that could plague many scholarly journals (quoted in Overholser 2003a). Over the years, the same goals have remained in place-to publish articles that avoid narrow thinking, ideological rigidity, and specialized technical jargon (Overholser 2008).

In addition to a journal's editor, the process is greatly influenced by members of the editorial board and an assortment of professionals who volunteer their time by serving as ad hoc reviewers for a manuscript or two each year. The editorial board includes experts representing a range of theoretical orientations. Over the years, the distinguished editorial board has included an impressive list of experts, including such notable leaders as David Cain, Giancarlo Dimaggio, Albert Ellis, Bob Friedberg, Les Greenberg, Emanuel Hammer, Jerome Frank, Jim Lantz, Paul Lysaker, Al Mahrer, Jules Masserman, Larry Riso, Max Rosenbaum, David Rudd, Virginia Satir, Ed Shafranske, John SommersFlanagan, Ernesto Spinelli, George Stricker, Hans Strupp, Thomas Szasz, Ed Watkins, Carl Whitaker, Joseph Wolpe, and many other experts in the field of psychotherapy.

I was first introduced to the journal in 1987, when I responded to call for papers that was advertised through the APA Monitor. I was thrilled to have one of my early articles on the treatment of a dependent personality disorder to be accepted and published in the journal (Overholser 1987). 
Fifteen years later, I was appointed Editor-in-Chief in April of 2002. Over the past 18 years, I have enjoyed the role, the work, and the camaraderie that has developed with many esteemed colleagues. When I was initially appointed as editor, I established goals and priorities for the journal, including the importance of protecting the central role that a therapeutic alliance plays in all cases of therapy and attempting to reduce the gap between academic researchers and community clinicians (Overholser 2002). In a society that seems to value medical research and drug treatments, the journal strives to emphasize the utility and protect the importance of psychological theories that explain the power of the mind (Greenberg and Goldman 2009; Overholser 2003b). Furthermore, the journal aims to highlight the best articles in the field, even those published in other scholarly journals (Overholser and Beale 2018; Overholser in press).

For any scholarly journal, the role of the editor is essential for all aspects of the publication, and assumes final responsibility for all editorial decisions (Committee on Publication Ethics: COPE 2016; Squires 1991). An editor serves as gatekeeper, only accepting manuscripts that are accurate, thoughtful, and make a genuine contribution to the field. Manuscripts should be evaluated for their originality, importance, clarity, and relevance to the aims of the journal (COPE 2016). The editor is responsible for ensuring all manuscripts are processed in a fair manner, providing authors with timely and constructive feedback about their work (Fischer 2004). The editor is guided by input from reviewers who help to ensure the fairness and integrity of the journal (COPE 2017). Reviewers should use their own professional experience to evaluate the quality of the paper, providing the editor with a broad knowledge base (Squires 1991). However, reviewers should avoid trying to revise the text into their own personal writing style (COPE 2017). Together, editor and reviewers work to protect the integrity, quality, visibility of the journal. The editor relies heavily on feedback from the reviewers, but ultimately provides an independent account of the value of each manuscript (Popkin 1989).

Editorial work can become quite complicated. A journal editor must guide the process of peer review, aiming to evaluate papers in a fair and impartial manner. Authors deserve constructive feedback that is received in a timely manner (Fischer 2004; Overholser 2011). This matter becomes complicated when processing my own editorials or manuscripts that are submitted by colleagues. Over the years, I have published a range of papers to express my views on the optimal treatment of depression as well as argumentative papers confronting the ideals and struggles of the field of psychotherapy more broadly. Previous editors have shared their views on important topics (Moses 2000; Parson 1990; Quaytman 1971, 1974). Currently, I have a special editor (Dr. Lauren Fisher) in charge of editorial review papers (including any manuscripts that
I helped to write), and a number of board members as reviewers who provide valuable feedback about each submitted paper, before it might be of publishable quality.

Over the past few years, the journal has begun to reject papers after a preliminary triage but without a full peer review if the paper seems to be focused on matters beyond the scope of contemporary psychotherapy or the research appears to be lacking in adequate methodological rigor. The triage process is used to save the time for authors and protect the reviewers so they remain available to consult on manuscripts of higher caliber. Too many papers seem to chase the latest fad topic, even though it may have little lasting appear (Overholser 2014a). Furthermore, it can be difficult to study issues relevant to psychotherapy when the research tries to examine clinical issues but relies on samples of convenience. The field has known for many years that there are dangers when extrapolating from purified research to real world settings (Bracht and Glass 1968). Thus, it makes sense to remain cautious about the utility or external validity of research that is conducted with college students (Henrich et al. 2010), internet surveys (Gosling and Mason 2015) and mTurk reports (Paolacci and Chandler 2014). In contrast, when the research has been conducted with medical patients or psychotherapy clients, the findings are more likely to shed light on important matters related to psychological treatments (Overholser 2014b).

The issue of analogue research can be examined through a simple analogy. I enjoy fishing in a good-sized lake. I find it peaceful, and the allure of finding and catching a trout or walleye is exciting. Lake fishing takes a lot of time and great patience. Some days, you can spend $6 \mathrm{~h}$ on the lake and catch one fish, or too often, none. As a child, my father once took me to a county fair that had an above-ground pool filled with 10,000 gallons of water and stocked with rainbow trout. For an entrance fee of $\$ 1.00$, I was able to fish in the pool, and I caught a few trout. However, even as a child, I found this arrangement a bit misguided, unrealistic, and not very satisfying. In the same way, fishing in a stocked pond or pool is similar to research that attempts to examine clinical psychology problems but limits the samples to high school students, college students, anonymous online surveys, or mTurk paid employees. The odds of catching something are much higher, but the situation is not real, natural, or satisfying. In contrast, data collection in a medical or psychiatric clinic can be exciting, exhausting, and quite satisfying. Thus, the journal actively encourages research that has been conducted with clinical samples of medical patients or psychiatric clients, using measures and procedures that encourage useful innovations for clinical practice (Overholser 2011). Publishing high quality clinical research studies can help practitioners to stay abreast of the latest advances in the field (Difilippo et al. 2003). 


\section{Evolution}

Over the past 50 years, there has been an evolution of psychotherapy reflected in the authors and publications found in the journal. The evolution can be seen both in the careers of long-standing clinicians whose ideas have grown or shifted across many years of clinical practice and in the evolution across different processes, theories, and styles of work in the field of psychotherapy.

Over the years, the therapeutic focus and theoretical orientation has evolved across the life of the journal. Early issues published many papers that involved speculative theories based on case examples that were proposed by lifelong clinicians. Sometimes, these clinical perspective papers were supported by detailed case studies. Many of the early articles were written by a single author who took the time to share their professional experience, theoretical views and informed opinions. More recently, journal articles rely on established theories and empirical research to support their claims. Today, most papers are being written by a collaborative team of co-authors and investigators, with few pure clinicians submitting manuscripts based on their own work in the clinical practice of psychotherapy.

Some respected authors have described their psychotherapy knowledge, skill and style that has evolved over the course of their career (e.g., Ekstein 1973; Whitaker 1973). For example, Mowrer (1973) described the enhanced modesty that developed over the past 10 years of his career. Mowrer (1973) explained that his view of psychotherapy developed during his undergraduate schooling and graduate training, sparking his early interest in psychoanalysis. However, over time, his faith in the psychoanalytic approach was shaken because of limited research support as well as his own unsuccessful time as a psychoanalytic patient. In a similar vein, Strupp (1971, p. 117) noted: "Once in the forefront of revolutionary change, psychoanalysis is with increasing monotony described as antiquated, passé, obsolete, and even defunct ... its therapeutic effectiveness has been questioned; its applicability to the vast problems of contemporary society is being doubted; and its status as a branch of the behavioral sciences appears to be approaching a nadir". This sad statement reflects some long-standing concerns with older theories, potentially encouraging innovation and evolution within the field of psychotherapy. As noted by Strupp (1971, p. 118), "the basic problem ... lies in the failure of psychoanalysis to have cultivated a spirit of open inquiry, a chronic unwillingness to welcome new ideas and techniques no matter where they might come from, a pervasive disinclination to question time-honored ideas and practices ... the science of psychoanalysis has been treated as the private property of a professional guild". Again, these ideas should help to promote, if not provoke, more collaborative work and diverse approaches to psychotherapy.

In contrast, some expert psychotherapists developed their ideas about psychotherapy early in their career, and remained staunch advocates of one particular approach. For example, Eysenck (1973, p. 22) claimed that "My approach to psychotherapy has not changed in the slightest since my first visit to the U.S.A." Furthermore, Eysenck (1973, p. 27) encouraged integrative approaches to psychotherapy, stating "perhaps the time has now come for a dialogue aimed at setting up a unified discipline of psychotherapy of which we can all be proud". Others (e.g., Greenwald 1971) also encouraged the integration of different theoretical models.

The importance of a solid therapeutic alliance is one aspect of psychotherapy that has remained respected over the years. Bowlby (1970) emphasized the importance of early bonding experiences on adult relationships. In a thoughtful review of his life and career, Wolpe (1973) emphasized the central value of the therapeutic reliance as a healing factor for most clients. Despite being a staunch advocate for the behaviorist movement, Wolpe respected the value of the therapeutic relationship. "The behavior therapist approaches his patients in a warm and friendly way that accords his conception of them as sufferers from unfortunate habits that they cannot help" (Wolpe 1973, p. 61). Likewise, Frank (1974, p. 118) noted: "Characteristics of the therapist related to his success are, a strong interest in his patients, ability to inspire their trust, and capacity to grasp what they are trying to say and reflect it to them". However, it was noted that a caring relationship was not enough for effective therapy, but the therapist needed to instill the courage needed to help clients grow through their pain (Whitaker 1973).

Cognitive-behavioral approaches have grown in strength because of the importance of research, and the willingness to examine critically what works and why it works. As noted by Strupp (1971, p. 120): "psychoanalysis has lost its scientific respectability in 1970 and, in many quarters has been degraded to an esoteric pursuit of a small cult who cater to affluent members of the upper middle class. .... The key is to be found in the abandonment of a smug attitude of narcissistic omnipotence". Sadly, today, this statement may now apply to cognitive-behavioral therapy, which is often seen and taught as the only approved form of psychotherapy.

Currently, the field of psychotherapy strives to meet the demands of evidence-based practice. Therefore, treatment manuals have been playing an important role in research, helping to ensure that each client in the study receives the same, or very similar treatment. Without such structured interventions, it can be difficult to objectively describe and replicate the treatment even when it has been found effective in reducing clients' symptoms. Unfortunately, when trainees and clinicians believe that all clients must be treated in a rigidly structured manner, then the unique adaptations and 
idiographic creativity are lost. There is a risk that clinical judgment will be devalued, and psychotherapists could be viewed as paraprofessional technicians guided by a manual (Shedler 2018). The current emphasis on evidence-based practice relies heavily on treatment manuals (Shedler 2018). However, manualized treatment has not been found to be more effective than traditional fluid styles of psychotherapy that remain more idiographic in their application (Shedler 2018; Truijens et al. 2019). Furthermore, it appears that degree of adherence to the manual does not have a significant impact on its effectiveness (Truijens et al. 2019). Finally, the importance of a client's subjective experience may be overshadowed by a focus on "objective" reality (Bugental 1969). Therapy can help clients become more aware of the subjective feelings, and learn to understand, accept, and express their emotions in a constructive manner (Greenberg 2006; Pos and Greenberg 2007). Although research often requires therapists to adhere to strict standards for each session, it seems more appropriate to allow a certain degree of flexibility to adapt a structured treatment plan to the unique needs of each client, perhaps guided by thematic modules. As noted long ago (Wolpe 1973). It is a mistake to view behavioral interventions as mechanically applied. Ekstein (1973) describes the therapist's role as analogous to a servant, who waits to find out what is needed and participates by serving a meal without manipulating the guest.

The field of psychotherapy continues to evolve. As the published articles become more heavily anchored in science, there is a risk that the notions become further removed from clinical practice. Many innovative papers are being published about the benefits of technology adapted psychotherapy (TAP: Overholser 2013), including internet-based information programs and smart phone applications that might help to educate clients. These technological advancements can help therapists to engage with youthful clients or connect with clients who struggle with mobility, transportation, or child care. It is important to use technology as a supplement to session dialogue so the field does not neglect the central importance of a strong therapeutic alliance as a vital ingredient in effective psychotherapy. As noted by Wolpe (1973, p. 59), "The common feature of all psychotherapies is a therapist's personal interaction with the client". Likewise, Frank (1974, p. 115) reflected on his time as a patient in two bouts of psychoanalysis and noted "The experiences with analysis .... left me convinced that the relationship with the therapist was much more important than his theory or technique". Frank (1974, p. 118) "Determinants of the success of psychotherapy of whatever form lie mainly in the patient and, to a lesser degree, in the therapist". However, the relationship is embedded within the interventions used by the therapist (Beutler and Harwood 2002).

Scholarly papers on psychotherapy have shifted in the style of authorship. Currently, few papers are published by a single author, but instead they reflect the input from a team of collaborators. Furthermore, most current papers are published by researchers with their primary job housed within an academic institution. Fewer papers are being published by full-time clinicians, enlarging the gap between the scientific side of psychotherapy from the realities of clinical practice. The integration of science and practice requires a clear and consistent focus on work that could help to improve the lives of mental health patients (Overholser 2007, 2008). Unfortunately, many faculty members value research over applied work (Overholser 2012), and have become more interested in the brain than the mind (Overholser 2003b).

As the field changes, there are risks that could affect the entire field of psychotherapy. When the majority of articles about psychotherapy have been written by academic researchers who no longer conduct psychotherapy sessions, there is a clear risk that the endorsed treatment strategies will not fit the realities of clinical practice. Not only does this hamper the utility of the published article, but it also derails the effective education of the next generation of psychotherapists. Without ongoing clinical activity, the mental health professional can easily lose touch with the importance of patience, persistence, flexibility, creativity, and sensitivity needed to conduct psychotherapy sessions. As noted by Ellis (1982, p. 25): "efficient therapy remains flexible, curious, empirically-oriented, critical of poor theories and results, and devoted to effective change". Ellis (1979) encourages an active therapist who vigorously debated the client's irrational beliefs.

The field of psychotherapy benefits from a sincere bond with the scientist-practitioner model (Overholser 2010, 2012), with faculty members maintaining weekly activity in the direct provision of clinical services (Overholser 2010). It seems essential to encourage the integration theoretical ideas, scientific evidence and clinical applications in psychology (Overholser 2008). Furthermore, it is important for faculty members who teach psychotherapy skills to remain active with their own clinical practice (Overholser 2019). In some situations, the integration of science and practice may be attained through the efforts of a collaborative team or a single individual who remains active in scholarship as well as the direct delivery of clinical services.

Over the years, the field of psychotherapy has seen an expansion of cognitive-behavioral strategies, with a subsequent reduction in articles that focus on experiential, existential, or interpretive approaches. This shift of orientation is aligned with the emphasis on research, as the CBT style is much more closely aligned with research methodology. Even aside from the theoretical orientation comes a shift of basic perspective and clinical focus. Instead of asking "who is this person and how can I be helpful?", the underlying attitude of many current therapists "What is the problem and how can I fix it?" An accurate diagnosis may help with initial plans 
for treatment but many other factors are important as well (Wampold et al. 2005). It seems important for the field of psychotherapy to respect its heritage and protect its future by valuing the special bond that develops between therapist and client. As noted by Fine (1974, p. 103), "psychotherapy is a philosophical approach to the problems of living".

\section{Evaluation}

Over the past 50 years, the field of psychotherapy has changed in many ways. These changes can be seen throughout the field, not just within the confines of one journal. The changes include several positive adaptations as well as several dysfunctional adjustments.

Over the past 50 years, positive changes include a willingness to confront basic ideas and change theoretical ideas as needed. Current journal articles typically cite the recent literature, using articles published during the past 5 years to support most of the claims being made in the paper. This is in contrast to older approaches, where the primary source remained the published works of Sigmund Freud, with little or no changes being made to Freudian ideology. As noted long ago by Wolman (1971, p. 21), "Psychoanalysis must not bask in the bright sun of Freud's discoveries. History has no mercy for epigones nor respect for fossils. Progress is not a one-time achievement, but a continuous process of craving and striving".

Over the past 50 years, there have been several negative changes to psychotherapy, including an overreliance on research support with a relative neglect of clinical experience. There is a desperate need for skilled clinicians who remain willing to take the time to write for publication, sharing the lessons they have learned from years of clinical experience. Likewise, there is a desperate need for academicians who remain active in the front-lines delivery of clinical services. The scientist-practitioner model provides the ideal forum for mental health professionals to integrate scholarly work with intervention skill, hopefully culminating in new ideas that can advance the field of psychotherapy.

It is essential to integrate science and practice, balancing the value of empirical support with the wisdom that derives from years of actual clinical experience (Overholser 2007). As noted by Hammer (1972, p. 82), "too much 'artistry' that is 'tender-minded' in quality results in treatment which is impressionistic and impulsive. ... Overemphasis on the 'scientific and tough minded' qualities in the therapist incurs the risk that the therapeutic experience will be reduced to an intellectual, emotionally rarified, detached exercise". In addition, it seems essential for psychotherapy instructors to remain active in the delivery of psychotherapy to ensure that the next generation of psychotherapists are trained to respect the realities of clinical practice (Overholser 2019).
Although some experts have focused on differentiating one form of therapy from another (e.g., Ellis 1976), there need be no more competition across treatment ideologies. The optimal treatment will be found through an integration, not a competition. As noted by Eysenck (1973, p. 20) "There is no evidence that psychotherapy, whether Freudian or other, cures or improves patients any more quickly or soundly than would happen anyway through spontaneous remission".

An assortment of common problems seem to underlie patient struggles, and can be addressed in psychotherapy. As noted by Mowrer (1973, p. 40), "Isolation, alienation, and loss of community manifestly play an important role in much psychopathology". Furthermore, "our contemporary society is often termed 'oceanic', its emphasis is upon material possession and the status they confer and group cohesion and all it implies for personal security is badly eroded" (Mowrer 1973, p. 41).

\section{Conclusions}

Over the past 50 years, the field of psychotherapy has grown in many ways, and so has the Journal of Contemporary Psychotherapy. There are many innovative approaches to the treatment of mental illness, and empirical support has helped to identify the necessary and sufficient components of client change strategies. In many ways, it seems like the field has evolved in new and important directions. However, upon closer inspection, some of the same issues are still present, as seen in the profound foreshadowing evidenced in various quotations from 40 to 50 years ago. For example, almost 50 years ago, it was claimed "Our times are times of high technological development and rapid change in cultural and moral values" (Wolman 1971, p. 26). However, many people could make the same statement about life today.

Over the past 50 years there have been some unfortunate changes in the field of psychotherapy. Despite my own background in and preference for cognitive and behavioral change strategies, it seems that the field has become narrowed to CBT, seen as superior to all other forms of psychotherapy. Today, there are few experts in treatment approaches that are based on existential therapy, gestalt therapy, reality therapy, and Adlerian therapy, and even worse, there is very little research support for these interventions. However, at a theoretical and pragmatic level, these approaches continue to provide useful ideas and helpful strategies when working with many different clients.

It seems likely that the core problem is the rabid insistence on treatment-outcome research to support any type of intervention (Shedler 2018). Because of the emphasis on empirical support, most researchers are drawn to a structured cognitive-behavioral orientation. Most research is conducted 
on university campuses, and too many studies rely on samples of convenience. Thus, there may be research to support mindfulness training for procrastination, but a 6-week manualized treatment provided by graduate trainees to two small samples of undergraduate students may not capture the realities of clinical practice. The findings seem unlikely to generalize to the standard care that is received by adults with chronic mental health problems seen in a community agency. Too many research studies may fail to reflect the realities of clinical practice.

The solution may be found in the scientist-practitioner model (Overholser 2010, 2012). When mental health professionals strive to maintain active involvement with both research and clinical practice, then there is hope for improvements in the field of psychotherapy. It seems important for full-time clinicians to remain informed of the latest developments in the field by reading scholarly journals, and by adapting their clinical practice to the latest findings in current research. Alternatively, it seems important for university professors who teach and write about psychotherapy to maintain weekly activity in the clinical services in which they claim expertise (Overholser 2019). Without any ongoing clinical activity, they easily lose touch with the nuances of psychotherapy, and are likely to mislead the younger generation.

The Journal of Contemporary Psychotherapy strives to integrate science and practice, preferring manuscripts written by authors who remain active with clinical practice as well as remaining firmly anchored in scholarship across treatment modalities, not framed as a competition between treatments. It seems important to reduce comparisons and contrasts across different theoretical views. There is little that can be gained from turf wars or tribalism that perpetuates arguments across different theoretical orientations (Wachtel 2018). As noted by Ellis (1969), "Human beings are exceptionally complex and there does not seem be any simple way in which they become what we call 'emotionally disturbed' nor does there seem to be a single monolithic way in which they can be helpful to be less self-defeating" (pp. 83-84). A simple view of psychotherapy was captured by Wolpe 1973, p. 59): "Psychiatric treatment has its target the elimination or alleviation of the varieties of human suffering and disability bound up with repetitive unadaptive behavior patterns".

A scholarly journal relies on erudition, changes through a gradual evolution, and incorporates major aspects of evaluation. Now, we conclude with a reflection of Eudaimonia. Eudaimonia is an obscure term that refers to a feeling of healthy contentment, satisfaction, and a sense of fulfillment. After reviewing the 50 years of JCP publication, I am not only satisfied but also quite impressed, with both the journal and the field of psychotherapy, what has been accomplished and the path toward future attainments. Although I remain concerned about a few matters, I am satisfied with the overall status of the field. Let me conclude with a thoughtful comment from Greenwald (1973, p. 34): "My hope is that we will utilize the discoveries of the past, the continuing discoveries in the variety of sciences of experience, that we will drop our need to form into camps, and we will work to develop and find a truly human oriented therapy, one in which as many people as possible can be helped to work together to create a better world for all of us".

\section{Editorial Postscript}

Given the focus of this paper, it seems essential to thank the various people who keep the journal running smoothly. First, I am greatly appreciative of the members of the editorial board, who review manuscripts, share insights, and sometimes assume the helms as guest editor of a special issue on a specialized topic. Next, I appreciate the time and expertise shared by a wide range of ad hoc reviewers. During the past 12 months, quite of mix of experts have reviewed manuscripts for the journal.

I am greatly appreciative of Springer Nature Publisher as the long-time publisher of the journal. The editorial staff, especially Carol Bischoff, have been long-time supporters of all aspect of the journal. Finally, I am thankful for the professional and administrative staff of the Long Island Consultation Center (LICC) as the founding institution and generous sponsor of the journal. Without the insight and integrity of the LICC, the Journal of Contemporary Psychotherapy would not exist.

\section{Compliance with Ethical Standards}

Conflict of interest The author has no conflict of interest to report.

\section{References}

Beutler, L., \& Harwood, T. (2002). What is and can be attributed to the therapeutic relationship? Journal of Contemporary Psychotherapy, 32(1), 25-33.

Bowlby, J. (1970). Disruption of affectional bonds and its effects on behavior. Journal of Contemporary Psychotherapy, 2(2), 75-86.

Bracht, G., \& Glass, G. (1968). The external validity of experiments. American Education Research Journal, 5(4), 437-474.

Bugental, J. (1969). Someone needs to worry: The existential anxiety of responsibility and decision. Journal of Contemporary Psychotherapy, 2(1), 41-53.

Committee on Publication Ethics. (2016). Code of conduct and best practice guidelines for journal editors. publicationethics.org.

Committee on Publication Ethics. (2017). Ethical guidelines for peer reviewers. publicationethics.org.

Difilippo, J., Sloan, D., Butler, R., Schulenberg, S., Lantz, J., \& Overholser, J. C. (2003). The future of psychotherapy: Visions and 
recommendations. Journal of Contemporary Psychotherapy, 33(4), 261-272.

Ekstein, R. (1973). Must I have a philosophy of psychotherapy. Journal of Contemporary Psychotherapy, 6(1), 4-11.

Ellis, A. (1969). Rational-emotive therapy. Journal of Contemporary Psychotherapy, 1(2), 82-90.

Ellis, A. (1976). The rational-emotive view. Journal of Contemporary Psychotherapy, 8(1), 20-28.

Ellis, A. (1979). The issue of force and energy in behavioral change. Journal of Contemporary Psychotherapy, 10(2), 83-97.

Ellis, A. (1982). Must most psychotherapists remain as incompetent as they now are? Journal of Contemporary Psychotherapy, 13(1), $17-28$.

Eysenck, H. J. (1973). Psychotherapy and the experimental approach. Journal of Contemporary Psychotherapy, 6(1), 19-27.

Fine, R. (1974). My approach to psychotherapy. Journal of Contemporary Psychotherapy, 6(2), 103-107.

Fischer, C. (2004). Editor as good steward of manuscript submissions. Journal of Scholarly Publishing, 36, 34-42.

Frank, J. (1974). My philosophy of psychotherapy. Journal of Contemporary Psychotherapy, 6(2), 115-120.

Gosling, S., \& Mason, W. (2015). Internet research in psychology. Annual Review of Psychology, 66, 26.1-26.26.

Greenberg, L. (2006). Emotion-focused therapy: A synopsis. Journal of Contemporary Psychotherapy, 36(2), 87-93.

Greenberg, R., \& Goldman, E. (2009). Antidepressants, psychotherapy or their combination. Journal of Contemporary Psychotherapy, 39(2), 83-91.

Greenwald, H. (1971). The integration of behavioral, existential and psychoanalytic therapy into direct decision therapy. Journal of Contemporary Psychotherapy, 4(1), 37-43.

Greenwald, H. (1973). My philosophy of psychotherapy. Journal of Contemporary Psychotherapy, 6(1), 29-34.

Hammer, E. (1972). The creative process in psychoanalytic treatment. Journal of Contemporary Psychotherapy, 4(2), 81-86.

Henrich, J., Heine, S., \& Norenzayan, A. (2010). The weirdest people in the world? Behavioral and Brain Sciences, 33, 61-135.

Moses, I. (2000). Is it ethical to deceive managed care companies? Journal of Contemporary Psychotherapy, 30(3), 217-237.

Mowrer, O. H. (1973). My philosophy of psychotherapy. Journal of Contemporary Psychotherapy, 6(1), 35-42.

Overholser, J. C. (1987). Facilitating autonomy in passive-dependent persons: An integrative model. Journal of Contemporary Psychotherapy, 17(4), 250-269.

Overholser, J. C. (2002). Contemporary psychotherapy: Goldmines and landmines. Journal of Contemporary Psychotherapy, 32, 249-258.

Overholser, J. C. (2003a). Contemporary psychotherapy: Looking backward, looking forward. Journal of Contemporary Psychotherapy, 33(4), 255-259.

Overholser, J. C. (2003b). Where has all the psyche gone: Searching for treatments that focus on psychological issues. Journal of Contemporary Psychotherapy, 33(1), 49-61.

Overholser, J. C. (2007). The Boulder model in academia: Struggling to integrate the science and practice of psychology. Journal of Contemporary Psychotherapy, 37, 205-211.

Overholser, J. C. (2008). Advancing the field of psychotherapy through innovation and integration in scholarly works. Journal of Contemporary Psychotherapy, 38(2), 97-104.

Overholser, J. C. (2010). Ten criteria to qualify as a scientist-practitioner in clinical psychology: An immodest proposal for objective standards. Journal of Contemporary Psychotherapy, 40(1), 51-59.

Overholser, J. C. (2011). Reading, writing, and reviewing: Recommendations for scholarly manuscripts at the graduate and professional level. Journal of Contemporary Psychotherapy, 41(1), 115-122.
Overholser, J. C. (2012). Behind a thin veneer: What lurks beneath the scientist-practitioner label? Journal of Contemporary Psychotherapy, 42(4), 271-279.

Overholser, J. C. (2013). Technology-Assisted Psychotherapy (TAP): Adapting computerized treatments into traditional psychotherapy for depression. Journal of Contemporary Psychotherapy, 43(4), $235-242$.

Overholser, J. C. (2014a). Chasing the latest fad: Confronting recent and historical innovations in mental illness. Journal of Contemporary Psychotherapy, 44(1), 53-61.

Overholser, J. C. (2014b). Protesting the decline but predicting the demise of clinical psychology: Can we avoid a total collapse? Journal of Contemporary Psychotherapy, 44(4), 273-281.

Overholser, J. C. (2019). Graduate training in psychotherapy: The importance of ongoing clinical activity for the training faculty. Counselling and Psychotherapy Research, 19, 264-273.

Overholser, J. C. (in press). "The nominees are .....": Awards for the integration of science and practice in psychology. Journal of Contemporary Psychotherapy, 49.

Overholser, J. C., \& Beale, E. E. (2018). "And the winner is ....": Awards for the integration of science and practice in psychology. Journal of Contemporary Psychotherapy, 48(4), 179-187.

Paolacci, G., \& Chandler, J. (2014). Inside the Turk: Understanding Mechanical Turk as a participant tool. Current Directions in Psychological Science, 23(3), 184-188.

Parson, E. (1990). Post-traumatic demoralization syndrome (PTDS). Journal of Contemporary Psychotherapy, 20(1), 17-33.

Popkin, R. (1989). The scholarly communication process in the Humanities: The role of the editor. The Serials Librarian, 17(3-4), $25-32$.

Pos, A., \& Greenberg, L. (2007). Emotion-focused therapy: The transforming power of affect. Journal of Contemporary Psychotherapy, 37(1), 25-31.

Quaytman, W. (1971). Psychotherapist's writing block. Journal of Contemporary Psychotherapy, 4(1), 53-57.

Quaytman, W. (1974). What makes a creative psychotherapist. Journal of Contemporary Psychotherapy, 6(2), 168-172.

Shedler, J. (2018). Where is the evidence for "evidence-based" therapy? Psychiatric Clinics of North America, 41, 319-329.

Squires, B. (1991). The role of the editor in peer review. The Serials Librarian, 19(3-4), 87-89.

Strupp, H. (1971). Some comments on the future of psychoanalysis. Journal of Contemporary Psychotherapy, 3(2), 117-120.

Truijens, F., Hulzen, L., \& Vanheule, S. (2019). To manualize, or not to manualize: Is that still the question? A systematic review of empirical evidence for manual superiority in psychological treatment. Journal of Clinical Psychology, 75, 329-343.

Wachtel, P. (2018). Pathways to progress for integrative psychotherapy: Perspectives on practice and research. Journal of Psychotherapy Integration, 28(2), 202-212.

Wampold, B., Lichtenberg, J., \& Waehler, C. (2005). A broader perspective: Counseling psychology's emphasis on evidence. Journal of Contemporary Psychotherapy, 35(1), 27-38.

Whitaker, C. (1973). My philosophy of psychotherapy. Journal of Contemporary Psychotherapy, 6(1), 49-52.

Wolman, B. (1971). Quo vadis, psychoanalysis? Journal of Contemporary Psychotherapy, 4(1), 23-26.

Wolpe, J. (1973). My philosophy of psychotherapy. Journal of Contemporary Psychotherapy, 6(1), 59-62.

Publisher's Note Springer Nature remains neutral with regard to jurisdictional claims in published maps and institutional affiliations. 